\title{
Effects of low-density lipoprotein extracted from egg yolk on preservation of chilled canine semen $\left(4^{\circ} \mathrm{C}\right)$
}

\author{
Van T. Nguyen, Anh T. P. Nguyen, Huy D. Nguyen, \\ Phuc L. G. Ha, \& Khanh T. V. Doan*
}

Faculty of Animal Science and Veterinary Medicine, Nong Lam University, Ho Chi Minh City, Vietnam

\begin{abstract}
ARTICLE INFO
Short communication

Received: July 01, 2021

Revised: September 14, 2021

Accepted: October 01, 2021
\end{abstract}

\section{Keywords}

Canine semen

Low-density lipoprotein

Preservation

\section{${ }^{*}$ Corresponding author}

Doan Tran Vinh Khanh

Email: khanhdoan@hcmuaf.edu.vn

\begin{abstract}
Low-density lipoprotein (LDL) derived from hen egg yolk has been considered an important component in the storage of canine semen; however, in Vietnam, there have not been many studies regarding this topic. Therefore, this study aimed to evaluate the effectiveness of LDL in the preservation of canine chilled semen in Vietnam. The assessment of semen samples was based on four criteria: storage time, motility, absolute viability, and integrity of acrosomal membrane at motility rate $0.9 ; 0.5$ and 0.3 . The semen samples collected were divided into three equal parts, each was then diluted with three different extenders and stored at $4^{\circ} \mathrm{C}$. The extenders were LDL + basic extender (LDL), egg yolk + basic extender (EY), and basic extender $(\mathrm{C})$.

The storage time of canine semen was recorded from the beginning of monitoring until the motility decreased to 0.3 . The storage time of the three extenders was in the order of EY $>$ LDL $>$ C, with 108 $\mathrm{h}, 60 \mathrm{~h}$, and $48 \mathrm{~h}$, respectively. The absolute viability of fertilizable sperm (Sa5) in the extender was EY (768), LDL (423) and C (280), which was significant $(P<0.001)$. The percentage of viable sperm with intact acrosome membrane at motility time $\mathrm{A}=0.9$ in LDL was $59.31 \%$, higher than that in EY (30.99\%). In the storage period from $\mathrm{A}=0.9$ to $\mathrm{A}=0.5$, the acrosome loss percentage of both $\mathrm{EY}$ and LDL decreased equally ( $7.30 \%$ and $7.23 \%)$, but the storage time of EY ( $84 \mathrm{~h})$ was longer than that of LDL $(48 \mathrm{~h})$.

In conclusion, the EY gave a longer storage time, higher absolute viability and longer maintain percentage of viable sperms and intact acrosome membrane compared to the LDL. However, within the first hours of storage, the percentage of viable sperm and intact acrosome membrane in the EY was lower than that in the LDL. Therefore, to preserve canine semen for a short time (less than $48 \mathrm{~h}$ ), the LDL extender should be used for better effectiveness.
\end{abstract}

Cited as: Nguyen, V. T., Nguyen, A. T. P., Nguyen, H. D., Ha, P. L. G., \& Doan, K. T. V. (2021). Effects of low-density lipoprotein extracted from egg yolk on preservation of chilled canine semen $\left(4^{\circ} \mathrm{C}\right)$. The Journal of Agriculture and Development 20(5), 8-15. 


\title{
Ảnh hưởng của lipoprotein tỷ trọng thấp chiết xuất từ lòng đỏ trứng gà trong bảo quản lạnh $\left(4^{\circ} \mathrm{C}\right)$ tinh dịch chó
}

\author{
Nguyễn Tử Văn, Nguyễn Thị Phương Anh, Nguyễn Đức Huy, \\ Hà Lê Gia Phúc \& Đoàn Trần Vĩnh Khánh*
}

Khoa Chăn Nuôi Thú Y, Trường Đại Học Nông Lâm TP.HCM, TP. Hồ Chí Minh

\section{THÔNG TIN BÀI BÁO}

Bài báo khoa học (ngắn)

Ngày nhận: 01/07/2021

Ngày chỉnh sửa: $14 / 09 / 2021$

Ngày chấp nhận: 01/10/2021

\section{Từ khóa}

Bảo quản

Lipoprotein tỷ trọng thấp

Tinh dịch chó

\section{*Tác giả liên hệ}

Đoàn Trần Vĩnh Khánh

Email: khanhdoan@hcmuaf.edu.vn

\section{TÓM TẮT}

Lipoprotein tỷ trọng thấp (LDL) chiết xuất từ lòng đỏ trứng gà đóng vai trò chính trong bảo quản tinh dịch chó, tuy nhiên tại Việt Nam chưa có nhiều nghiên cứu về vấn đề này. Mục tiêu của nghiên cứu nhằm đánh giá tác động của LDL trong bảo quản lạnh tinh dịch chó. Kết quả được đánh giá qua các chỉ tiêu gồm thời gian bảo quản, hoạt lực, sức sống tuyệt đối và tính nguyên vẹn của màng acrosome tại các mức hoạt lực 0,$9 ; 0,5$ và 0,3 . Ba loại môi trường được sử dụng gồm môi trường căn bản + lòng đỏ trứng gà ( $\mathrm{EY})$, môi trường căn bản $+\mathrm{LDL}(\mathrm{LDL})$ và môi trường căn bản $(\mathrm{C})$.

Thời gian bảo quản tinh dịch chó trong ba loại môi trường từ khi bắt đầu theo dõi đến khi hoạt lực về 0,3 giảm dần theo thứ tự $\mathrm{EY}>$ LDL > C, tương ứng với 108 giờ, 60 giờ và 48 giờ. Sức sống tuyệt đối của tinh trùng còn khả năng thụ tinh (Sa5) trong các môi trường lần lượt là $\mathrm{EY}$ (768), LDL (423) và C (280), khác biệt rất có ý nghĩa với $P<0,001$. Tỷ lệ tinh trùng sống - còn nguyên vẹn màng acrosome tại thời điểm hoạt lực $=0,9$ trong môi trường LDL $(59,31 \%)$ cao hơn trong $\mathrm{EY}$ (30,99\%). Tuy nhiên, khi hoạt lực giảm từ 0,9 dến 0,5 thì tỷ lệ tinh trùng sống - còn màng acrosome ở cả môi trường $\mathrm{EY}$ và $\mathrm{LDL}$ đều giảm tương đương nhau ( $7,30 \%$ và $7,23 \%)$, nhưng thời gian bảo quản của EY ( 84 giờ) lâu hơn so với LDL (48 giờ).

Kết quả cho thấy môi trường $\mathrm{EY}$ có thời gian bảo tồn, sức sống tuyệt đối và duy trì tỷ lệ tinh trùng sống - còn màng acrosome tốt hơn môi trường LDL. Tuy nhiên, ngay sau pha chế, tỷ lệ tinh trùng sống - còn màng acrosome đã rất thấp. Do đó, khi bảo quản tinh dịch trong thời gian ngắn (dưới 48 giờ) thì sử dụng LDL sẽ cho kết quả tốt, với tỷ lệ tinh trùng sống - còn màng acrosome cao.

\section{1. Đặt Vấn Đề}

Trong những năm gần đây, nuôi chó làm thú cưng đang trở nên phổ biến tại Việt Nam, đặc biệt là các giống chó đẹp, quý hiếm và thân thiện. Từ đó, nhu cầu về nhân giống các giống chó này cũng tăng theo. Phương pháp nhân giống chủ yếu được sử dụng hiện nay là giao phối trực tiếp, phương pháp này gây hao tổn đực giống, dẫn tới giảm thời gian khai thác, cũng vì các lý do trên nên chi phí một lần phối giống khá cao. Vì vậy, gieo tinh nhân tạo trên chó đang dần phổ biến, phương pháp này đảm bảo được sức khỏe của đực giống do một lần khai thác tinh dịch có thể phân thành nhiều liều tinh và bảo quản dài ngày hơn vì thế giảm số lần khai thác đực giống, đảm bảo sức khỏe và tăng thời gian khai thác.

Để việc gieo tinh nhân tạo đạt hiệu quả cao, ngoài yếu tố kỹ thuật còn phải đảm bảo chất lượng của tinh dịch tốt, do đó môi trường bảo quản tinh dịch trong gieo tinh nhân tạo đóng vai trò quan trọng. Tại nước ta hiện nay, môi trường bảo quản tinh chó còn nhiều hạn chế nên phải nhập khẩu từ nước ngoài với giá thành cao, làm tăng chi phí một lần gieo tinh. Do đó, cần đẩy mạnh các nghiên cứu trong nước về các chất bổ sung trong môi trường bảo quản nhằm cải thiện chất lượng môi trường, giúp giảm chi phí gieo tinh 
nhân tạo tại nước ta.

Một trong số các chất thường được sử dụng để bổ sung vào môi trường bảo quản là lòng đỏ trứng gà bởi khả năng bảo vệ tinh trùng khỏi sự sốc lạnh và cung cấp dinh dưỡng trong quá trình bảo quản lạnh (Moussa \& ctv., 2002). Tuy nhiên, việc sử dụng lòng đỏ trứng gà tăng khả năng vấy nhiễm vi sinh từ đó làm cho mẫu tinh nhiễm nội độc tố ảnh hưởng đến khả năng thụ tinh. Bên cạnh đó, những nghiên cứu gần đây lại cho rằng phần lớn hiệu quả bảo quản đến từ sự có mặt của lipoprotein tỉ trọng thấp (LDL) trong lòng đỏ trứng (Moussa \& ctv., 2002).

Từ những thực tế trên, đề tài nghiên cứu được thực hiện nhằm đánh giá tác động của LDL trong bảo quản tinh dịch chó.

\section{Vật Liệu và Phương Pháp Nghiên Cứu}

\subsection{Tách chiết LDL từ lòng đỏ trứng gà}

\subsubsection{Vật liệu}

Trứng gà tươi được thu thập trong vòng 24 giờ sau khi đẻ tại trại Nghiên Cứu Ứng Dụng (Applied Research Farm) thuộc Trường Đại học Nông Lâm TP.HCM. Trứng gà được loại bỏ hoàn toàn phần lòng trắng, phần lòng đỏ được lăn trên giấy (Newstar 101, Trung Quốc) để loại bỏ phần lòng trắng còn sót lại trên màng lòng đỏ. Sau đó, màng lòng đỏ được rạch và thu lòng đỏ vào cốc.

\subsubsection{Phân tách plasma}

Phần bào tương trứng trong lòng đỏ được phân tách theo phương pháp của McBee (Bee \& Cotterill, 1979). Lòng đỏ sau khi phân tách được pha loãng bằng một lượng dung dịch $\mathrm{NaCl} 0,17 \mathrm{M}$ có thể tích tương đương và khuấy bằng máy khuấy từ HI190M (Hanna Instruments, Anh) trong 1 giờ ở $4^{\circ} \mathrm{C}$. Dung dịch này được $\mathrm{ly}$ tâm bằng máy ly tâm (HERMLE, Đức) ở mức 12.500 vòng/phút trong 15 phút ở $4^{\circ} \mathrm{C}$, thu phần nổi (bào tương trứng) loại bỏ phần hạt nhỏ lắng bên dưới.

\subsubsection{Chiết xuất LDL}

Bào tương trứng $(\mathrm{pH} \approx 6,0)$ được trộn với $5 \%$ PEG-4000 (HiMedia, Ấn Độ) bằng máy khuấy từ ở $4^{\circ} \mathrm{C}$ trong 1 giờ. Hỗn hợp này tiếp tục được ly tâm với vận tốc 15.000 vòng/phút ở $4^{\circ} \mathrm{C}$ trong 15 phút. Phần vật chất nổi là phần giàu $\mathrm{LDL}$ được thu lại.

\subsection{Bảo quản tinh dịch chó}

\subsubsection{Thú thí nghiệm}

Mẫu tinh dịch được thu nhận từ 1 chó đực, đủ 1 năm tuổi, thuộc giống chó ta có khối lượng $12 \mathrm{~kg}$. Mẫu tinh được thu thập bằng âm đạo giả với tần suất 1 lần/tuần, liên tục trong 20 tuần. Tổng số mẫu tinh thu được là 15 mẫu và sau khi pha loãng có 8 mẫu tinh đạt tiêu chuẩn (hoạt lực trên 0,8 , số lượng từ $200 \times 10^{6}$ tinh trùng/lần xuất tinh trở lên, tỷ lệ kỳ hình nhỏ hơn $10 \%$ được sử dụng trong thí nghiệm.

\subsubsection{Môi trường bảo quản}

Mỗi mẫu tinh đạt tiêu chuẩn được chia thành ba phần bằng nhau để pha loãng với 3 loại môi trường bảo quản gồm: môi trường căn bản $(\mathrm{C})$, môi trường căn bản + lòng đỏ trứng gà (EY) và môi trường căn bản + LDL (LDL) (Bảng 1), môi trường căn bản dựa trên môi trường Tris fructose của Iguer - Ouada \& Verstegen (2001). Tất cả các môi trường kể trên đều được điều chỉnh độ $\mathrm{pH}$ ở 6,7 - 6,8 bằng thiết bị đo $\mathrm{pH}$ của Hanna Instruments, Anh.

\subsubsection{Bảo quản lạnh}

Mỗi mẫu tinh (đạt tiêu chuẩn sử dụng) được chia thành 3 phần bằng nhau, sau đó mỗi phần sẽ pha loãng với từng loại môi trường theo tỷ lệ 1:1. Sau khi pha loãng tinh dịch sẽ được để ổn định ở nhiệt độ phòng trong 15 phút. Sau đó kiểm tra lại hoạt lực, các mẫu tinh có điểm hoạt lực từ 0,9 trở lên sẽ được chia vào các ống eppendorf 0,5 $\mathrm{mL}$ và bảo quản trong tủ lạnh đã cài đặt nhiệt độ ở $4^{\circ} \mathrm{C}$.

\subsection{Các chỉ tiêu theo dõi}

Mẫu tinh sau khi khai thác (tinh nguyên) được kiểm tra thu thập số liệu và đánh giá phẩm chất tinh dịch gồm thể tích $(\mathrm{V})$, hoạt lực $(\mathrm{A})$, nồng độ tinh trùng $(\mathrm{C})$, kỳ hình và tổng số tinh trùng có khả năng thụ tinh (V.A.C).

Mẫu tinh pha chế với môi trường sẽ được kiểm tra, thu thập số liệu để đánh giá thời gian bảo tồn tinh dịch và đánh giá sức sống tuyệt đối $(\mathrm{Sa})$ theo công thức của Nguyen \& Nguyen (1997) thông qua việc theo dõi định kỳ sự thay dổi hoạt lực theo thời gian. Sự thay đổi hoạt lực bắt đầu được đánh giá sau khi pha chế 15 phút và định kỳ mỗi 
Bảng 1. Môi trường bảo quản tinh dịch $^{1}$

\begin{tabular}{lccc}
\hline Thành phần trong $100 \mathrm{~mL}$ & $\mathrm{C}$ & $\mathrm{EY}$ & LDL \\
\hline Tris $(\mathrm{g})$ & 3,03 & 3,03 & 3,03 \\
Glucose $(\mathrm{g})$ & 1,25 & 1,25 & 1,25 \\
Citrate.natri.2 $\mathrm{H}_{2} \mathrm{O}(\mathrm{g})$ & 1,81 & 1,81 & 1,81 \\
Penicillin $(\mathrm{mg})$ & 100,00 & 100,00 & 100,00 \\
Streptomycin $(\mathrm{mg})$ & 100,00 & 100,00 & 100,00 \\
Lòng đỏ trứng gà $(\mathrm{mL})$ & 0,00 & 20,00 & 0,00 \\
LDL $(\mathrm{g})$ & 0,00 & 0,00 & 6,00 \\
\hline
\end{tabular}

${ }^{1} \mathrm{C}$ : môi trường căn bản; $\mathrm{EY}$ : môi trường căn bản + lòng đỏ trứng gà; LDL: môi trường căn bản + low-density lipoprotein (LDL).

12 giờ cho tới khi mức hoạt lực $\mathrm{A}=0,3$. Tại các mức hoạt lực $\mathrm{A}=0,9$ các mẫu tinh sẽ được nhuộm acrosome theo phương pháp của Kovács \& Foote (1992) để đánh giá tính nguyên vẹn màng acrosome; tại mức hoạt lực $\mathrm{A}=0,5$ và $\mathrm{A}=0,3$ chỉ nhuộm acrosome theo phương pháp Kovács \& Foote 2 mẫu tinh có thời gian bảo tồn cao nhất để đánh giá tính nguyên vẹn màng acrosome.

\subsubsection{Phẩm chất tinh dịch}

\section{Thể tích (Volume):}

Tinh dịch sau khi khai thác được cho vào ống falcon có chia vạch để kiểm tra thể tích tinh dịch.

\section{Đánh giá hoạt lực (Activity):}

Tiến hành: nhỏ 1 giọt tinh lên lam kính sạch và khô, sau đó đặt phiến kính lên tiêu bản và đặt lên kính hiển vi xem ở vật kính $10 \mathrm{x}$ và $40 \mathrm{x}$.

Xem kính: hoạt lực tinh trùng được đánh giá dựa theo mức hoạt động tiến thẳng của tinh trùng và cho điểm theo thang điểm của Milovanov (1962).

\section{Đánh giá nồng độ (Concentration):}

Tiến hành: Sử dụng buồng đếm hồng bạch cầu (Hirschmann, Đức). Pha loãng tinh dịch chó 200 lần bằng $\mathrm{NaCl} 3 \%$. Dùng micropipette nhỏ hỗn hợp lên buồng đếm đã đậy sẵn phiến kính. Sau đó đặt buồng đếm lên kính hiển vi, tiến hành đếm 5 ô lớn (4 ô bốn góc và 1 ô chính giữa). Khi đếm thì đếm đầu tinh trùng, không đếm lạ̣p lại.

Kết quả được tính theo công thức:

$\mathrm{C}=50000 \times \mathrm{n} \times \mathrm{b}=\mathrm{n} \times 10^{6}$

Trong đó:

C: nồng độ tinh trùng trong $1 \mathrm{~mL}$ tinh dịch

$\mathrm{n}$ : số lượng tinh trùng đếm được trong 5 ô lớn

b: hệ số pha loãng (200 lần)

\section{Đánh giá kỳ hình:}

Sử dụng phương pháp nhuộm Kovács (1992) để kiểm tra kỳ hình tinh trùng.

Tiến hành: Nhỏ 1 giọt tinh dịch chó và 1 giọt trypan blue 0,27\% lên lam kính sau đó trộn đều rồi dàn mỏng và để khô. Lam kính tiếp tục được ngâm trong dung dịch cố định (gồm $14 \mathrm{~mL}$ formaldehyde, $86 \mathrm{~mL} \mathrm{HCl} 1 \mathrm{~N}$ và $0,2 \mathrm{~g}$ neutral red) trong 5 phút sau đó rửa với nước cất và để khô. Sau khi nhuộm trong dung dịch Giemsa 7,5\% ở $40^{\circ} \mathrm{C}$ trong 4 - 5 tiếng, lam kính được rửa với nước cất, để khô và kiểm tra ở vật kính x100.

\subsection{2. Đánh giá sức sống tuyệt đối của tinh trùng}

Theo Nguyen \& Nguyen (1997), sức sống tuyệt đối của tinh trùng được tính dựa theo công thức:

$\mathrm{Sa}=\sum$ at

Trong đó:

Sa: chỉ số sức sống tuyệt đối của tinh trùng

a: sức hoạt động thực tế của tinh trùng trong khoảng thời gian giữa hai lần kiểm tra (lần trước và lần sau thời điểm cần tính)

t: thời gian mà tinh trùng duy trì được sức hoạt động a

Thời gian được tính theo công thức:

$\operatorname{tn}=(\mathrm{Tn}+1-\mathrm{Tn}-1) / 2$

Trong đó:

tn: thời gian mà tinh trùng có sức hoạt động giữa 2 lần kiểm tra

Tn+1: thời gian bảo quản từ lúc bắt đầu thí nghiệm đến lần kiểm tra sau

Tn-1: thời gian bảo quản từ lúc bắt đầu thí nghiệm đến lần kiểm tra trước

Ngay tại lúc bắt đầu thí nghiệm, vì $\mathrm{n}=0$ nên Tn-1 $=0$. Do đó, ta có:

$$
\operatorname{tn}=(\operatorname{Tn}=1) / 2
$$


Khi kết thúc thí nghiệm vì $\mathrm{Tn}+1=0$. Do đó, ta có:

$$
\operatorname{tn}=(\operatorname{Tn}-\mathrm{Tn}-1) / 2
$$

\subsubsection{Nhuộm màng acrosome của tinh trùng}

Tại các thời điểm $\mathrm{A}=0,9$ (thời điểm bắt đầu theo dõi), $\mathrm{A}=0,5$ (thời điểm tinh trùng còn khả năng thụ tinh) và $\mathrm{A}=0,3$ (thời điểm kết thúc theo dõi) các mẫu tinh được tiến hành nhuộm theo phương pháp Kovács \& Foote (1992) để kiểm tra tính nguyên vẹn của màng acrosome.

\subsection{Xử lý số liệu}

Xử lý thông kê bằng phần mềm Minitab (Minitab ${ }^{\circledR}$ 16.2.0, Minitab Pty Ltd, Úc) với mô hình tuyến tính tổng quát (GLM) và xác định mức độ khác biệt ý nghĩa của các nghiệm thức bằng trắc nghiệm $\mathrm{F}$.

\section{Kết Quả và Thảo Luận}

\subsection{Phẩm chất tinh nguyên}

Phẩm chất tinh nguyên được thể hiện qua Bảng 2. Thể tích tinh nguyên toàn phần trung bình là $5,81 \mathrm{~mL} /$ lần xuất tinh, cao hơn kết quả của một số tác giả tại Việt Nam (Thai, 2005; Bui, 2010). Theo Johnston (1991), thể tích tinh dịch chó thường dao động từ $1-30 \mathrm{~mL}$, tuy nhiên thể tích tinh dịch không tương quan với chất lượng tinh dịch trên chó.

Xét về nồng độ tinh trùng, các mẫu tinh có nồng độ trung bình là 99,38 x $10^{6}$ tinh trùng $/ \mathrm{mL}$. Theo Freshman (2002), nồng độ tinh trùng của chó nên nằm trong khoảng $250-300 \times 10^{6}$ tinh trùng mỗi đợt xuất tinh. Tổng số tinh trùng có khả năng thụ tinh (VAC) là $575,19 \times 10^{6}$ tinh trùng, cao hơn kết quả của Thai (2005) và Bui (2010). Tỷ lệ kỳ hình trung bình là 1,88\%, thấp hơn kết quả của Iguer - Ouada \& Verstegen (2001) là $15 \%$.

\subsection{Thời gian bảo tồn}

Thời gian bảo tồn giữa các môi trường được thể hiện qua Hình 1.

Tại mức hoạt lực 0,9: Tại thời điểm $\mathrm{A}=0,9$ không có sự khác biệt về thời gian bảo tồn giữa các môi trường với $P>0,05$.

Tại mức hoạt lực 0,5: Tại $\mathrm{A}=0,5$ (tinh trùng

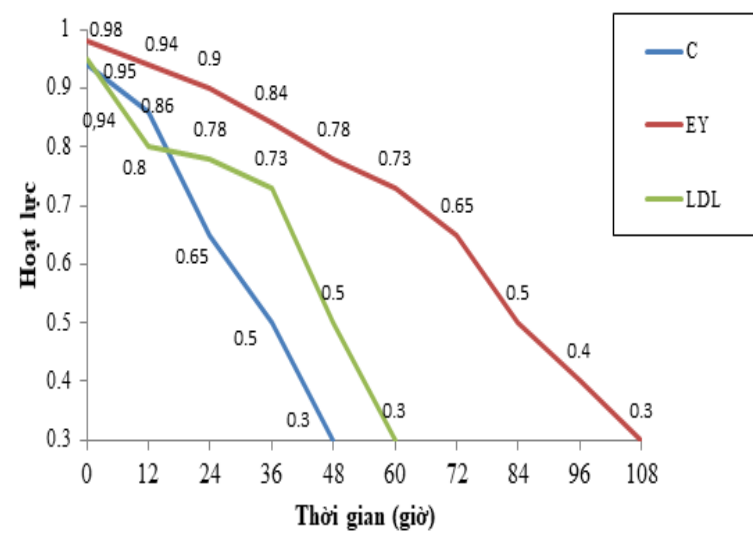

Hình 1. Thời gian bảo tồn tinh dịch của các môi trường. C: môi trường căn bản; $\mathrm{EY}$ : môi trường căn bản + lòng đỏ trứng gà; LDL: môi trường căn bản + low-density lipoprotein (LDL).

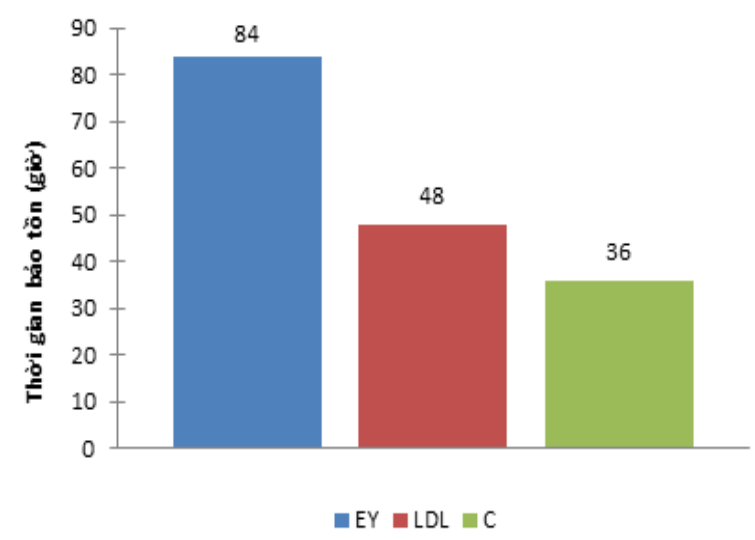

Hình 2. Thời gian bảo tồn tinh dịch tại $\mathrm{A}=0,5$. $\mathrm{C}$ : môi trường căn bản; $\mathrm{EY}$ : môi trường căn bản + lòng đỏ trứng gà; LDL: môi trường căn bản + low-density lipoprotein (LDL).

còn khả năng thụ tinh), môi trường $\mathrm{EY}$ (84 giờ) có thời gian bảo tồn dài hơn so với môi trường LDL (48 giờ) và môi trường $\mathrm{C}$ (36 giờ) với $\mathrm{P}<$ 0,001 (Hình 2). Tuy nhiên, giữa môi trường LDL và $\mathrm{C}$ khác biệt không có ý nghĩa $(P>0,05)$. Bên cạnh đó, thời gian bảo tồn của Iguer - Ouada \& Verstegen (2001) với môi trường Tris - glucose là 13 ngày cao hơn so với môi trường $\mathrm{EY}$. Sự chênh lệch này có thể được lý giải là do các yếu tố như nhiệt độ, khí hậu môi trường, thao tác thực điều kiện phòng thí nghiệm và trứng gà dùng để bổ sung. Ngoài ra, các chất có tác dụng bảo vệ tinh trùng có trong EY như lecethin, các lipoprotein và hàm lượng $\mathrm{EY}, \mathrm{LDL}$ được bổ sung cũng có thể tác động lên kết quả.

Tại mức hoạt lực 0,3: Thời gian bảo tồn của các 
Bảng 2. Phẩm chất tinh nguyên được sử dụng trong thí nghiệm

\begin{tabular}{|c|c|c|c|c|c|}
\hline Số mẫu (n) & Thể tích (mL) & Hoạt lực & $\begin{array}{l}\text { Nồng độ } \\
\left(10^{6} \text { tinh }\right. \\
\text { trùng/mL) }\end{array}$ & Kỳ hình (\%) & $\begin{array}{l}\text { Tổng số tinh trùng } \\
\text { có khả năng thụ } \\
\text { tinh }\left(\times 10^{6} \text { tinh }\right. \\
\text { trùng/lần })\end{array}$ \\
\hline 8 & $5,81 \pm 1,16$ & $0,98 \pm 0,03$ & $99,38 \pm 9,68$ & $1,88 \pm 1,65$ & $569,43 \pm 116,85$ \\
\hline
\end{tabular}

môi trường cho tới khi $\mathrm{A}=0,3$ được thể hiện qua Hình 3 cho thấy rằng môi trường EY (108 giờ) cho thời gian bảo tồn dài hơn môi trường LDL (60 giờ) và môi trường $\mathrm{C}$ (48 giờ) với $P<0,001$. Môi trường LDL (60 giờ) và $\mathrm{C}$ (48 giờ) khác biệt không có ý nghĩa.

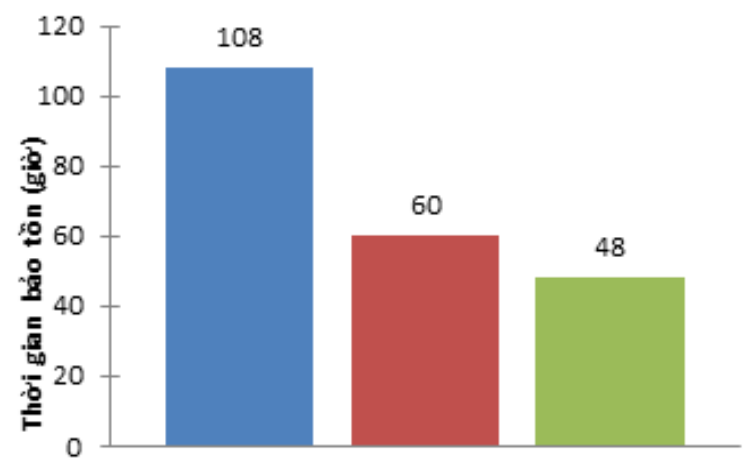

\section{EY $\square \mathrm{LDL}=\mathrm{C}$}

Hình 3. Thời gian bảo tồn tinh dịch tại $\mathrm{A}=0,3$. $\mathrm{C}$ : môi trường căn bản; EY: môi trường căn bản + lòng dỏ trứng gà; LDL: môi trường căn bản + low-density lipoprotein (LDL).

\subsection{Sức sống tuyệt đối}

Nếu chỉ dựa vào thời gian bảo tồn tinh dịch để đánh giá chất lượng của một môi trường bảo quản là chưa đầy đủ mà cần phải theo dõi thêm chỉ số sức sống tuyệt đối của tinh trùng còn khả năng thụ tinh (Sa5) để so sánh khả năng thụ tinh trong quá trình tồn trữ nhằm có thêm cơ sở khẳng định chất lượng của các môi trường bảo quản.

Kết quả Bảng 3 cho thâyy sức sống tuyệt của tinh trùng còn khả năng thụ tinh (Sa5) khi pha với môi trường $\mathrm{EY}$ (768) cao hơn môi trường LDL (423), khác biệt rất có ý nghĩa với $P<0,001$, thấp hơn kết quả của Bui (2010) là 4001,68. Qua các kết quả trên, môi trường $\mathrm{EY}$ có chỉ số Sa5 cao hơn các môi trường còn lại với sự khác biệt rất có ý nghĩa $(P<0,001)$.
Bảng 3. Sức sống tuyệt đối của tinh trùng còn khả năng thụ tinh (Sa5)

\begin{tabular}{ccc}
\hline Môi trường & Sa5 & $P$ \\
\hline EY & $768,00^{\mathrm{a}} \pm 144,30$ & \\
LDL & $423,00^{\mathrm{b}} \pm 151,60$ & 0,001 \\
C & $280,50^{\mathrm{c}} \pm 86,30$ & \\
\hline
\end{tabular}

a, b, c Các trung bình trong cùng một cột có chữ cái theo sau khác nhau thì sự khác biệt rất có ý nghĩa thống kê, với $P$ $<0,001, \pm$ độ lệch chuẩn (SD). C: môi trường căn bản; EY: môi trường căn bản + lòng đỏ trứng gà; LDL: môi trường căn bản + low-density lipoprotein (LDL).

\subsection{Tính toàn vẹn của màng acrosome}

Tính toàn vẹn của màng acrosome cũng là một chỉ tiêu ảnh hưởng lớn đến khả năng thụ tinh. Do đó, nếu chỉ dựa vào mức hoạt lực $\mathrm{A}$ (tỷ lệ số tinh trùng còn sống và có năng lực thụ tinh) thì chưa đảm bảo được khả năng thụ thai của tinh trùng. Vì vậy, tính toàn vẹn của màng acrosome cần được đánh giá tại các mức hoạt lực $\mathrm{A}=0,5$ và $\mathrm{A}=0,3$ để khẳng định lại hiệu quả bảo tồn tinh dịch ở phòng thí nghiệm của 2 môi trường tốt nhất. Kết quả nhuộm màng acrosome được phân loại như Hình 4.

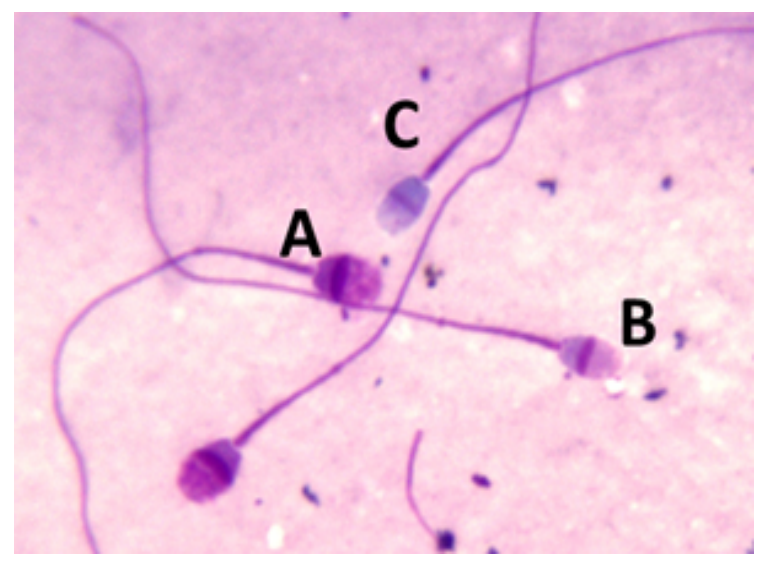

Hình 4. Kết quả nhuộm màng acrosome tinh trùng chó (vật kính $\times 100$ ). A: sống - còn màng acrosome; $\mathrm{B}$ : sống - mất màng acrosome; $\mathrm{C}$ : chết - mất màng acrosome. 


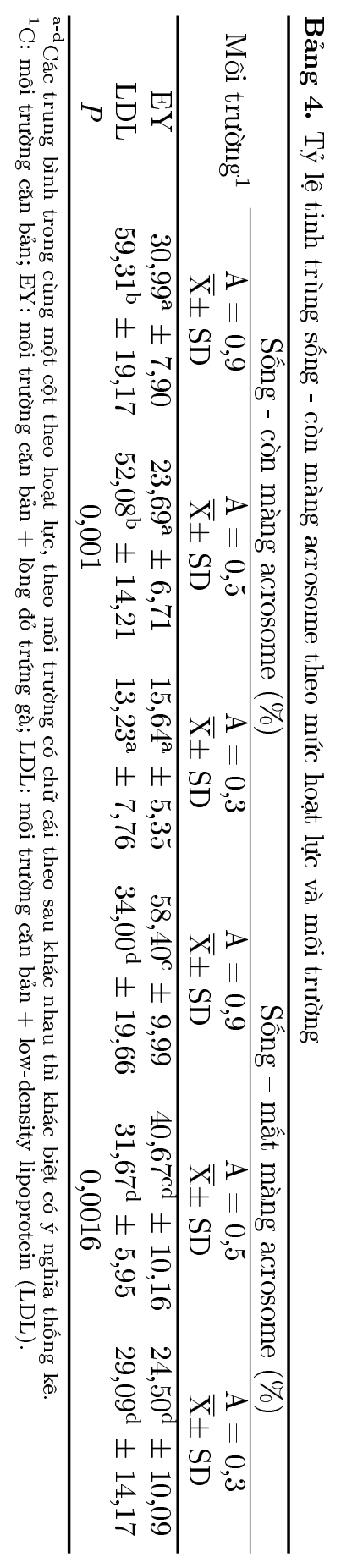

Dựa vào kết quả trong Bảng 4 có thể thấy rằng tại mức hoạt lực $\mathrm{A}=0,9$ (bắt đầu tính thời gian bảo quản), tỷ lệ tinh trùng sống - còn màng acrosome trong môi trường bổ sung LDL $(53,91 \%)$ cao hơn so với môi trường bổ sung $\mathrm{EY}(30,99 \%)$ với $P$ $<0,001$ và tỷ lệ tinh trùng sống - mất màng acrosome của EY $(58,40 \%)$ cao hơn LDL $(34,00 \%)$ với $P<0,05$. Ngay sau khi pha chế tinh dịch màng acrosone ở môi trường bổ sung EY bị hư hại nhiều hơn đáng kể so với môi trường có LDL.

Ở mức hoạt lực $\mathrm{A}=0,5$, tỷ lệ tinh trùng sống - còn màng acrosome trong môi trường bổ sung EY $(23,69 \%)$ thấp hơn so với môi trường bổ sung LDL $(52,08 \%)$ với $P<0,001$. Tuy nhiên, trong khoảng hoạt lực giảm từ $\mathrm{A}=0,9$ dến $\mathrm{A}=0,5$ thì tỷ lệ tinh trùng sống - còn màng acrosome của cả 2 môi trường đều giảm tương đương nhau $(7,30 \%$ ở môi trường bổ sung $\mathrm{EY}$ và $7,23 \%$ ở môi trường có bổ sung $\mathrm{LDL}$ ) và thời gian bảo quản tinh dịch dến mức $\mathrm{A}=0,5$ của $\mathrm{EY}$ ( 84 giờ) lại dài hơn so với LDL (48 giờ).

Ở mức hoạt lực $\mathrm{A}=0,3$, tỷ lệ tinh trùng sống - còn màng acrosome ở môi trường bổ sung $\mathrm{EY}(15,64 \%)$ và môi trường bổ sung $\mathrm{LDL}$ $(13,23 \%)$ là tương đương nhau và rấtthấp. Điều này làm giảm hiệu quả dậu thai khi gieo tinh trên chó cái là rất lớn.

Kết quả trên có thể thấy môi trường EY có khả năng duy trì tỷ lệ tinh trùng sống - còn màng acrosome tốt hơn so với LDL, nhưng ngay sau khi pha chế tinh dịch thì môi trường $\mathrm{EY}$ có tỷ lệ hư hại màng acrosome nhiều hơn môi trường có bổ sung LDL. Việc này có thể do tác động của một số chất có tính ức chế tinh trùng có trong EY ngay sau khi pha chế tinh dịch. Trong thời gian bảo quản tác động của các chất này giảm tác động lên tinh trùng và các chất có lợi cho bảo quản như lecethin, lipoprotein có trong EY phát huy tác dụng bảo quản lên việc bảo vệ và duy trì màng acrosome của tinh trùng tốt hơn LDL. Hàm lượng $\mathrm{EY}$ và LDL được bổ sung cũng sẽ có ít nhiều ảnh hưởng đến khả năng bảo vệ màng acrosome của tinh trùng trong thời gian bảo quản.

\section{Kết Luận}

Môi trường bổ sung EY có thời gian bảo tồn, sức sống tuyệt đối cao hơn môi trường bổ sung LDL và duy trì tỷ lệ tinh trùng sống - còn màng acrosome lâu hơn. Tuy nhiên, ngay sau khi pha chế thì tỷ lệ tinh trùng sống - còn màng acrosome 
đã rất thấp nên có thể ảnh hưởng tới tỷ lệ đậu thai. Do đó, khi bảo quản tinh dịch trong thời gian ngắn (dưới 48 giờ) thì sử dụng LDL sẽ cho kết quả tốt, với tỷ lệ tinh trùng sống - còn màng acrosome cao. Tuy nhiên, cần thực hiện thêm các nghiên cứu về hàm lượng $\mathrm{EY}$ và $\mathrm{LDL}$ được bổ sung vào môi trường và hiệu quả đậu thai trên thú cái sau bảo quản để đánh giá toàn diện hơn việcdùng môi trường bổ sung $\mathrm{EY}$ và $\mathrm{LDL}$ để bảo quản tinh dịch trong thời gian dài (trên 48 giờ).

\section{Lời Cảm Ơn}

Tập thể tác giả xin chân thành cảm ơn Trường Đại học Nông Lâm TP.HCM đã tài trợ kinh phí thực hiện (Mã số: CS - SV - CNTY - 04).

\section{Tài Liệu Tham Khảo (References)}

Bee, L., \& Coteerill, O. (1979). Ion-exchange chromatography and electrophoresis of egg yolk proteins. Journal of Food Science 44(3), 656-667.

Bui, H. T. T. (2010). Preserving ability of some extenders in canine semen (Unpublished bachelor's thesis). Nong Lam University, Ho Chi Minh City, Vietnam.

Freshman, J. L. (2001). Clinical management of the subfertile stud dog. Veterinary Clinics of North America: Small Animal Practice 31(2), 259-269.

Iguer-Ouada, M., \& Verstegen, J. P. (2001). Long-term presevervation of chilled canine semen: effect of commercial and laboratory prepared extenders. Theriogenology 55(2), 671-684.
Johnston, S. D. (1991). Performing a complete canine semen evaluation in a small animal hospital. Veterinary Clinics of North America: Small Animal Practice $21(3), 545-551$.

Kovács, A., \& Foote, R. H. (1992). Viability and acrosome staining of bull, boar and rabbit spermatozoa. Biolechnic \& Histochemistry 67(3), 119-124.

Milovanov, V. K. (1962). Biology of reproduction and artificial insemination of animals. Moscow, Russia: Selhozizdat.

Moussa, M., Martinet, V., Trimeche, A., Tainturier, D., \& Anton, M. (2002). Low density lipoproteins extractedv from hen egg yolk by an easy method: cryoprotective effect on frozen-thawed bull semen. Theriogenology 57(6), 1695-1706.

Nguyen, A. T., \& Nguyen, D. Q. (1997). Artificial insemination of cattle and poultry. Ha Noi, Vietnam: Ha Noi Publishing House.

Thai, H. M. T. (2005). Possibility of collecting dog semen and preservation effect of some dog semen extenders (Unpublished master's thesis). Nong Lam University, Ho Chi Minh City, Vietnam. 